\title{
Entre as crenças pessoais e a formação acadêmica: como professores de biologia que professam fé religiosa ensinam evolução?
}

\section{Between personal beliefs and the academic background: how do biology teachers who profess a religious faith teach evolution?}

\author{
Pedro Teixeira ${ }^{1}$. Marcelo Andrade ${ }^{2}$
}

\begin{abstract}
Resumo: O debate entre ciência e religião tem marcado os últimos séculos, com implicações atuais para o ensino de ciências. Passados cento e cinquenta anos do lançamento de "A origem das espécies", vivemos em um mundo não menos religioso do que o enfrentado por Darwin. Como professores de biologia que professam uma fé religiosa cristã lidam com a tensão entre criacionismo e evolução em sua prática pedagógica? Para responder a esta questão, foram realizadas entrevistas semiestruturadas com dez professores, e analisou-se o conteúdo de suas falas, utilizando referenciais históricos, epistemológicos e éticos. Os entrevistados reconhecem a importância da evolução para o ensino de biologia, porém se dividem quanto ao ensino de criacionismo. Conclui-se que é preciso aprofundar o diálogo entre religião e ciência na sala de aula, tendo em vista suas diferenças epistemológicas e históricas e o respeito às crenças de estudantes e docentes.
\end{abstract}

Palavras-chave: Ensino de biologia. Religião. Evolução. Criacionismo. Ciência e religião.

\begin{abstract}
The debate over science and religion has marked the last centuries, with current implications for Science teaching. After 150 years since The origin of species, we still live in a world no less religious than that confronted Darwin. How do Biology teachers, who profess a Christian religious faith, deal with the existing tension between Creationism and Evolution in their teaching? To answer this question, semistructured interviews were conducted with ten teachers, and the content of their speech was analyzed, using historical, epistemological and ethical frameworks. The interviewees realize the importance of evolution to biology teaching, but feel divided over teaching Creationism. The conclusion is that it is necessary to deepen the discussion between Religion and Science in the classroom, taking into account the epistemological and historical differences and respect for student's and teachers' beliefs.
\end{abstract}

Keywords: Biology teaching. Religion. Evolutionism. Creationism. Science and religion.

\footnotetext{
${ }^{1,2}$ Departamento de Educação, Centro de Teologia e Ciências Humanas, Pontifícia Universidade Católica do Rio de Janeiro (PUC-Rio), Rua Marquês de São Vicente, 225, Gávea, CEP 22453-900, Rio de Janeiro, RJ, Brasil. E-mail: teixeirapp86@gmail.com
} 


\section{Introdução}

As tensões entre ciência e religião não estão restritas ao debate atual. Remontam o surgimento da chamada ciência moderna, na revolução científica do século XVI. Pensadores como Galileu e Newton, embora estivessem dando os primeiros passos na formação do que hoje chamamos de pensamento científico, eram profundamente religiosos (HENRY, 1998). A história da relação entre o campo científico e o religioso, no entanto, está marcada por conflitos, diálogos, afastamentos e aproximações.

Um importante capítulo dessa história foi a publicação de "A Origem das Espécies" de Charles Darwin (1859). Darwin defende a ideia da evolução dos seres vivos por meio de modificações graduais e extinções ao longo de milhões de anos, por meio do processo de seleção natural. Tal teoria causou grande impacto no meio científico e forte reação por parte de membros de diferentes religiões, por ir de encontro às crenças criacionistas, em especial a cristã, para a qual, segundo o Gênesis, Deus criou o universo e todos os seres vivos tais como eles são hoje, bem como o ser humano a sua imagem e semelhança (MAYR, 1982).

A evolução é considerada o conceito mais importante da biologia atualmente (MAYR, 2009). Ela responde a diversas perguntas sobre as formas dos seres vivos atuais e extintos e, cada vez mais, amplia os horizontes das ciências biológicas. Com os avanços de outras áreas e o desenvolvimento de técnicas mais precisas, a biologia evolutiva tem se tornado um campo com bases mais sólidas e de constante inovação.

Passados mais de cento e cinquenta anos da publicação de "A Origem das Espécies", vivemos num mundo não menos religioso que o de Darwin. Além disso, a secularização não está necessariamente vinculada à consciência individual, como defende Berger (2001, p. 10):

Com certeza, a modernização teve alguns efeitos secularizantes, em alguns lugares mais do que em outros. Mas ela também provocou o surgimento de poderosos movimentos de contra-secularização. Além disso, a secularização a nível societal não está necessariamente vinculada à secularização a nível da consciência individual. Algumas instituições religiosas perderam poder e influência em muitas sociedades, mas crenças e práticas religiosas antigas ou novas permaneceram na vida das pessoas, às vezes assumindo novas formas institucionais e às vezes levando a grandes explosões de fervor religioso.

Dessa forma, podemos destacar o crescimento de diversos grupos religiosos que reagem à secularização, como é o caso de algumas denominações evangélicas pentecostais e neopentencostais no Brasil, que vêm crescendo fortemente nas últimas décadas (NERI, 2011). De acordo com Berger (2001), não há hoje elementos suficientes para afirmar que as crenças religiosas virão a se extinguir.

Nesse contexto, esta pesquisa partiu da hipótese de que o professor de biologia que professa uma fé religiosa cristã lida com dois campos fundamentais para a sua identidade, que possivelmente se confrontam como divergentes no seu processo de formação pessoal e profissional. Por um lado, ser religioso: a religião e suas convicções pessoais com base no criacionismo. Por outro, ser professor de ciências: o conhecimento científico, sua formação acadêmica e 
atuação profissional como docente responsável pelo ensino da evolução. Assim, esta investigação teve como objetivo central entender como esses professores lidam com a tensão entre criacionismo e evolução; se e como ensinam a evolução biológica e o criacionismo; e quais as razões, estratégias e dificuldades que apontam para sua prática pedagógica, tendo em vista suas identidades religiosa e profissional.

\section{Sobre as escolhas metodológicas}

Nesta investigação, optou-se por uma abordagem qualitativa. Tal escolha se deu em função do problema de pesquisa e dos objetivos propostos, que se caracterizam por uma compreensão possível sobre as relações entre as crenças religiosas de professores de biologia que professam uma fé cristã e suas práticas pedagógicas relacionadas aos temas da evolução biológica e do criacionismo.

$\mathrm{Na}$ pesquisa aqui apresentada, os sujeitos são professores de biologia do Ensino Médio. Optou-se por este nível de ensino porque é neste momento da Educação Básica que a temática da evolução é mais explorada e aprofundada nas aulas de biologia. Foram entrevistados/as dez professores/as que atuam ou já atuaram no Ensino Médio. Chegamos a esses docentes através de redes de contato e da lista de e-mails da Sociedade Brasileira de Ensino de Biologia. Cinco são católicos, um batista, um testemunha de Jeová, um presbiteriano, um metodista e um espírita ${ }^{3}$. Sobre a formação acadêmica, vale registrar que nove possuem estudos de pós-graduação (Apêndices 1 e 2).

Dentre as estratégias possíveis, foi selecionada para esta investigação, além da revisão de bibliografia sobre os temas centrais, o uso de entrevistas semiestruturadas. Zago (2003, p. 301) afirma que elas expressam:

Realidades, sentimentos e cumplicidades que um instrumento com respostas estandardizadas poderia ocultar, evidenciando a infundada neutralidade científica daquele que pesquisa. $\mathrm{O}$ encontro com um interlocutor exterior ao universo social do entrevistado representa, em vários casos, a oportunidade de este ser ouvido e poder falar de questões sociais que lhe concernem diretamente.

Assim, optamos por realizar entrevistas, porém nos mantivemos flexíveis aos novos elementos que surgiram ao longo dos depoimentos. Para a elaboração do roteiro de entrevista, foram definidos temas e, no interior destes, questões mais específicas para auxiliar na definição da problemática, hierarquizando o que era central e o que era periférico na investigação, de acordo com a orientação teórico-metodológica de Zago (2003). Também foi requisitado aos professores que assinassem um termo de consentimento da participação na pesquisa,

\footnotetext{
${ }^{3}$ É preciso registrar que adotamos a autodenominação dos sujeitos de pesquisa. Todos os entrevistados se identificaram como cristãos.
} 
no qual lhes foi garantido anonimato. Foi solicitado, ainda, o preenchimento de uma ficha que forneceu dados para a análise dos seus perfis profissionais e religiosos.

Vale frisar que o objeto desta pesquisa esteve circunscrito ao conteúdo dos discursos dos/as entrevistados/as. Reconhecemos os limites de um trabalho com estas características, mas estamos convencidos de que a metodologia escolhida propiciou os elementos necessários para se alcançarem os objetivos e para contribuir no avanço da discussão sobre a relação de professores/as de biologia que professam uma fé religiosa criacionista com o ensino do conhecimento científico com base na evolução.

Após o cumprimento das entrevistas, elas foram transcritas. Foram realizadas análises sobre os relatos adquiridos com auxílio do software ATLAS.ti (2011). A seguir, apresentamos parte dessas análises, sobretudo aquelas relacionadas às práticas pedagógicas dos entrevistados, com foco no processo de ensino-aprendizagem. Assim, o objetivo deste trabalho é apresentar a análise do conteúdo da fala dos depoentes sobre suas concepções, estratégias e dificuldades sobre o ensino da evolução biológica e as tensões com suas crenças religiosas pessoais.

\section{Por que e como ensinar evolução?}

A defesa de que a teoria da evolução é central para a biologia enquanto disciplina acadêmica é o principal argumento para que o ensino da disciplina escolar também seja organizado pela evolução como seu eixo estruturante. A importância da evolução para o ensino de biologia vem sendo apontada por diversos estudos (ALMEIDA; FALCÃO, 2010; MEGLHIORATTI; CALDEIRA; BORTOLOZZI, 2006; TIDON; LEWONTIN, 2004). Este argumento também está presente nos documentos oficiais brasileiros. Os Parâmetros Curriculares Nacionais do Ensino Médio (PCNEM), por exemplo, enfatizam a importância de uma abordagem evolutiva e ecológica de diversos conceitos biológicos:

[...] a variabilidade, como conseqüência de mutações e de combinações diversas de material genético, precisa ser entendida como substrato sobre o qual age a seleção natural; a própria ação da natureza selecionando combinações genéticas que se expressam em características adaptativas, também precisa considerar a reprodução, que possibilita a permanência de determinado material genético na população. A interpretação do processo de formação de novas espécies demanda a aplicação desses conceitos [...]. (BRASIL, 1998, p. 18)

Tal importância fica ainda mais explícita nas Orientações Curriculares para o Ensino Médio (OCEM):

Um tema de importância central no ensino de Biologia é a origem e evolução da vida. Conceitos relativos a esse assunto são tão importantes que devem compor não apenas um bloco de conteúdos tratados em algumas aulas, mas constituir uma linha orientadora das discussões de todos os outros temas. [...] A presença do tema 
origem e evolução da vida ao longo de diferentes conteúdos não representa a diluição do tema evolução, mas sim a sua articulação com outros assuntos, como elemento central e unificador no estudo da biologia. (BRASIL, 2006, p. 22, grifos nossos)

Fica evidente que os objetivos expressos nesses documentos sobre o ensino de biologia acompanham o pensamento da biologia enquanto área acadêmica na qual a evolução é seu eixo orientador. Mais do que isso, percebe-se nas OCEM a intenção de que essa temática atue, também, como um eixo central do ensino.

Dessa maneira, foi perguntado aos sujeitos de pesquisa se ensinavam evolução e por quê. Nove entrevistados/as responderam afirmativamente e apenas uma professora declarou que não:

Não! Não! Quando eu chego nessa área de evolução eu converso como estou
conversando com você. Nós fazemos assim, grupos de estudo. [...] Porque aqui
também é um grupo bem religioso. [...] É um grupo muito religioso. [...] Alguns
pastores e bispos e tal que colocam pra eles somente uma verdade e se você for
entrar muito nessa questão você vai criar atrito com a comunidade. Então quan-
do você já começa a falar, você já encontra atritos com os alunos, mesmo eu me
colocando como alguém que também acredita na teoria criacionista. Mas mesmo
assim! Alguns mais fundamentalistas ficam revoltados quando eu coloco. (Mar-
ta, batista)

Marta deixa claro que ensina evolução, mas que não a aborda da mesma maneira que outros conteúdos. Segundo ela, a religião dos educandos é um fator que gera resistências ao tema, pois suas crenças são discordantes dos conceitos de evolução biológica. A alternativa encontrada pela professora é apresentar a evolução como uma hipótese tão válida do ponto de vista científico quanto a explicação criacionista. A evolução é considerada, na perspectiva acadêmica, um fato (MAYR, 1982, 2009; RIDLEY, 2006), e serve de eixo para os conhecimentos em biologia. Assim, tal como defendem os PCNEM, ela deve ser trabalhada em sala pelo/a professor/a de biologia. Porém, esta orientação curricular oficinal não se verifica no depoimento de Marta, o que nos leva a considerar que a evolução é um tema de tensão para a professora.

Não queremos defender aqui uma postura autoritária que ignore as diferentes crenças dos estudantes. É interessante que a professora ouça e respeite suas crenças. Contudo, isso não invalida o ensino de biologia no seu eixo orientador, tal como proposto pelos PCNEM. Além disso, com essa postura, a professora abre mão da oportunidade de fazer com que os estudantes tenham contato com ideias diferentes daquelas de seu contexto religioso.

\footnotetext{
${ }^{4}$ Todos os nomes atribuídos aos entrevistados são fictícios. Os depoimentos foram transcritos sem a correção de eventuais erros gramaticais identificados nas falas.
} 
Os demais professores disseram que ensinam evolução. No entanto, chama a atenção que Moisés, Raquel e Jeremias admitem que o primeiro motivo para ensinar evolução é o fato de estar listada no currículo da disciplina.

Porque eu ensino evolução? Porque está no programa da escola, esse é o primeiro passo. (Moisés, católico)

Primeiro porque tá no programa. (Raquel, católica)

Ah, eu ensino porque tá lá no meu cronograma. Se tivesse lá no meu cronograma que não era pra ensinar eu não ia ensinar. Ou então, sei lá. Ou eu ia comentar de uma outra forma com eles, mas eu sou funcionário da escola. Isso é um negócio muito crítico pra gente professor. A gente tem que cumprir o cronograma. (Jeremias, presbiteriano)

É interessante notar que, para esses professores, a importância do ensino da evolução está no currículo da disciplina escolar. Nota-se, nos três casos, uma referência explícita à prioridade do conteúdo programático em detrimento ao conhecimento, ou, ainda, uma opção do professor. Além dessas afirmações, outras foram recorrentes, como a alusão à centralidade da evolução para a biologia:

Bom, eu acho primeiro assim, muitos, até como se eu for me pegar como aluna de biologia, as coisas fazem muito mais sentido se você pensar à luz da evolução. [...] Porque você entende as coisas dentro de um contexto histórico, dentro de um contexto de interações, aí eu acho que vai fazendo mais sentido por causa disso... (Sarah, católica)

Porque eu acho que tudo na ciência é a luz da evolução, já dizia um autor que na biologia nada faz sentido a não ser à luz da evolução. Então a evolução é o primeiro passo pra se ensinar ciências. [...] Então você vê que aconteceu essa evolução nas estruturas dos animais e, enfim, nos sistemas. Então, ensinar evolução porque eu acho que a ciência está pautada na evolução, ainda mais depois dessa genética que foi descoberta, essa evolução ganhou mais sentido ainda. (Moisés, católico)

Mas assim, eu acho que evolução é um tema central da biologia hoje mesmo. Eu acho que é uma das coisas mais importantes que a gente deve ver. Muitos livros didáticos estão sendo feitos com foco na evolução. Você vê o livro todo programado pra começar na quimica da vida até chegar no último ser vivo mais adaptado, mais derivado [...]. Como essa vida surgiu até ela chegar ao ponto que tá, né? Acho que tudo passa pela evolução, é fundamental. (Jeremias, presbiteriano)

Nestes depoimentos, percebe-se, claramente, referência ao célebre artigo "Nada em biologia faz sentido senão à luz da evolução” (DOBZHANSKI, 1973), referência obrigatória 
nos estudos de evolução. O uso da expressão "à luz da evolução" evidencia isso, assim como a indicação de que não há sentido se não há essa luz. Sarah, Moisés, Nazaré e Jeremias concluíram sua graduação há menos de seis anos, o que talvez seja um indício de que a abordagem dessa temática na formação de professores de ciências tenha ganhado um maior impulso, o que também se reflete na produção acadêmica da área, tendo em vista os trabalhos citados anteriormente. Sarah, inclusive, explicita a sua experiência como estudante de biologia. Vale lembrar que Moisés e Jeremias haviam dito que a principal razão era o currículo e, posteriormente, o caráter axial da evolução para as ciências biológicas.

Vale destacar que outros dois professores explicam de forma diferente porque ensinam evolução:

Por que eu acho que se você vai falar de biologia, que é o estudo da vida, você tem que falar do começo da vida. Eu sou bem didática [...] você tem que ter começo, meio e fim. Fim não tem, então, eu começo onde tudo começou, na origem da vida, as teorias evolucionistas. (Eva, católica)

A evolução eu acho que até na hora de você organizar o programa da biologia, ela vem também pensando a nivel da evolução, ou você começa do ser mais inferior, você começa lá das moléculas que formam os seres vivos, ou seja, do menor para o maior; ou você começa do maior para o menor. Nesse estudo que você faz, você passa sempre para um grau de complexidade maior e esse grau de complexidade, ele é dito, ele é encarado como sendo um grau da evolução sim, da evolução que vai acontecendo nos diferentes seres. (Adão, católico)

Nesses dois depoimentos percebemos uma referência ao ensino de evolução para entender como a vida surgiu até chegar às formas atuais. Por meio das expressões "fim não tem" e "evolução vai acontecendo", é possível identificar que, para Adão e Eva, a evolução acontece ainda hoje. Estes professores seguem a ideia da centralidade da evolução para a biologia, posto que se referem à área como um todo. Contudo, Adão deixa transparecer uma visão do processo evolutivo como progresso, quando afirma que "começa do ser mais inferior". Tal como afirma Mayr (1982, 2009), o paradigma dominante na biologia defende que a evolução continua atualmente e não é teleológica, ou seja, não há uma progressão em direção de um determinado fim. Se, por um lado, os professores reconhecem a continuidade do processo evolutivo nos dias de hoje, por outro, é evidente uma contradição na fala de Adão, pois argumenta que há, na evolução, uma concepção de finalidade (teleologismo).

Quando questionados sobre as dificuldades para o ensino da evolução, os professores relatam diferentes estratégias pedagógicas a fim de superar algumas resistências.

A escola recebe muito aluno que é evangélico e o evangélico tem uma visão diferenciada. Ele não aceita muita coisa. Então, tinha aluno que se recusava a fazer o trabalho, teve muito aluno que se recuson a fazer este tipo de trabalho, até de ir ver uma exposição [sobre Darwin]. Eles não gostam muito. (Maria, testemunha de Jeová) 
Primeiro que a gente comecou vendo lá que foram descobertas fósseis, dinossauros... Nossa então ninguém nunca viu um dinossauro? Então, como é que você tá me falando que existe? Aí a pessoa que é criacionista... Você então viu dinossauro? Existe ainda dinossauro? Você viu dinossauro? Alguém viu? Ah, professora porque acharam... Ah! Então acharam o fóssill! Então você concorda que existiram os dinossauros? Concordo. Se ele acreditava que tudo que foi formado existe até hoje... Então eu só jogo uma sementinha... (Raquel, católica)

Nem quando eu trabalhava no colégio ' $X$ ”, que é um colégio da própria doutrina que eu sigo, en não trabalhava sozinha nisso. Em sala de aula entrava o capelão do colégio acompanhado da minha colega... [...] A gente fazia uma roda. Então, tirava todas as carteiras, nós sentávamos em roda, o capelão, eu, a menina que trabalhava no laboratório que fazia doutorado também, que era [denominação religiosa] e nós trazíamos todas as pessoas que podiam acompanhar aquilo ali praquilo ali não ser traduzido em situações de constrangimento para nós profissionais e para o colégio. Porque a gente tinha que ter todo o cuidado com as pessoas que estavam ali que não eram [denominação religiosa]. Então, você vê o cuidado que se tem que ter para trabalhar esse assunto, entendeu? O capelão tava ali pra falar sobre a Bíblia. Eu e a menina távamos ali pra falar sobre a ciência em si. E a gente faz̨ia um debate e eles perguntavam, perguntavam e a gente tinha coisa que não sabia responder. Mas esse assunto nunca foi tratado assim de uma forma muito incisiva. (Marta, batista)

Os depoimentos de Maria, Raquel e Marta apresentam as dificuldades no ensino da evolução diante das crenças dos estudantes. Por um lado, Maria e Raquel apresentam uma postura mais crítica, apresentando questionamentos que visam ampliar a percepção dos estudantes. Por outro, Marta relata um esforço de conciliação - ou, talvez, um temor - frente à profissão de fé dominante entre os estudantes e a direção da escola.

Nazaré, Moisés e Eva, entre outros, demonstram atenção ao tema, a partir de alguns eixos estruturantes. Ainda que apresentem um planejamento didático clássico para o ensino de ciências, estes professores articulam o conhecimento científico e a abordagem consolidada nos livros didáticos de ciências.

Então, eu tento ir um pouquinho por aí, começando a falar das características do planeta que permitiram a origem da vida, como eram os primeiros seres vivos e depois as modificações que eles sofreram, até mesmo pelas modificações ambientais, os processos de mutação, as teorias que tentavam explicar e a que hoje em dia é mais aceita. (Nazaré, metodista)

Eu tento ensinar evolução comparativamente, mostrando exemplos, indícios de que ela realmente existiu. Novamente, quando eu ensino a evolução, eu não tomo como princípio a existência de Deus. Então, eu tomo a evolução como a biologia quer que ensine, sem essa opinião religiosa, justamente porque seria uma pseudociência. Então, é à luz da evolução mesmo, simples e puro. (Moisés, católico) 
Mas origem da vida eu trato no primeiro dia de aula, nas primeiras semanas de aula. Sempre falo com todas as turmas, ai eu falo das teorias evolucionistas. $O$ conceito de evolução, aquelas coisas técnicas: analogia, homologia, freqüência populacional, essas coisas técnicas mesmo do conteúdo [de] evolução é no terceiro ano, mas a parte de teorias evolucionistas eu já dou no primeiro ano. Eu acho que tem que ter uma seqüência, falar do começo antes de falar do resto. (Eva, católica)

Esses quatro professores estruturam suas aulas em um eixo semelhante: origem da vida; teorias evolucionistas de Lamarck e Darwin; evidências evolutivas; e neodarwinismo. Podemos encontrar estrutura semelhante nos livros didáticos, conforme análise de Almeida e Falcão (2010), e nas obras sobre essa temática (MAYR, 2009; RIDLEY, 2006). É interessante notar ainda que há uma preocupação em mostrar que o conhecimento científico é transitório e não está isolado de uma cultura e de uma época. Além disso, Moisés também afirma que procura separar essas discussões da fé religiosa, pois, em sua visão, isso não corresponderia ao pensamento científico.

Ainda sobre as práticas docentes, Maria foi a única entrevistada que relatou algumas estratégias que procuram dialogar com a cultura de referência dos educandos. A professora apresenta, basicamente, quatro estratégias: (1) linguagem visual; (2) pesquisa; (3) leitura de jornal, e (4) expansão da sala de aula para outros espaços.

Eu levei os alunos para ver aquela exposição de Darwin [...]. As faixas de anos entre os processos, as diferenças que aconteceram. Até porque é um assunto para este tipo de aluno que a gente recebe aqui, fazer uma leitura dessa, ele acha muito cansativo, então, com este aluno você tem que ser muito no visual. Então, o que a gente procura, pelo menos eu, particularmente, o que sempre busquei aqui foi fazer com eles pesquisassem sobre o assunto, porque pesquisando eles teriam informações mais diferenciadas e poderiam chegar a uma conclusão. Eu sempre trabalhei com eles, muito, a questão do visual, para que eles pudessem ter esta memorização. E a observação mesmo, eu peço para traz̧er reportagens que eles possam ler e discutir. (Maria, testemunha de Jeová)

Considerando os depoimentos dos sujeitos de pesquisa, podemos perceber a força que o currículo oficial tem na seleção de conteúdos e em suas práticas pedagógicas. Nota-se, também, que os professores de formação mais recente (Apêndice 2) foram os que enfatizaram de maneira mais clara a centralidade do conteúdo de evolução para a disciplina escolar de biologia. Nesta perspectiva, outro ponto marcante foi a semelhança do planejamento destes professores com o desenho clássico dos livros didáticos de ciências e biologia, o que demonstra que o ensino da evolução ainda fica articulado com os materiais de apoio didático. Por fim, vale destacar que as crenças religiosas predominantes entre os educandos ou, mesmo, das instituições escolares aparecem, nos depoimentos, como uma dificuldade para o processo de ensino-aprendizagem do tema evolução. No entanto, os professores relatam algumas estratégias a fim de contorná-las. 


\section{Criacionismo: entre as crenças pessoais e o ensino de ciências}

Quando questionados/as sobre se e como tratam o criacionismo em suas aulas, metade dos/as entrevistados/as adota uma postura na qual se apresenta uma clara diferenciação entre o estatuto epistemológico da ciência e o caráter transcendental do conhecimento religioso.

Ensinar criacionismo caberia a um professor de teologia, porque é uma visão religiosa, [...] a minha aula é uma aula de biologia, a ciência em si não vai se propor a discutir isso, se Deus existe, se Deus não existe. Na verdade isso é uma questão muito mais metafísica filosófica do que científica. Então, acho que isso não cabe no espaço da aula de biologia. Se algum aluno quiser discutir isso fora da sala de aula, eu vou falar, estou dando a minha opinião como pessoa, não como professora, e mesmo eu dando minha opinião, assim, a minha opinião era essa de que são coisas diferentes, são conbecimentos diferentes. [...] Mas assim, eu faço essa discussão com eles, mas ai eu não vou me aprofundar dentro da parte religiosa, porque en acho que não é o objetivo da disciplina escolar biologia. (Sarah, católica)

Não, não ensino criacionismo, até porque, eu acho que isto é uma questão de opinião e nós vivemos em um país que tem liberdade religiosa. Eu não posso... É o que eu te falei, eu não misturo as coisas, o que está no meu conteńdo é evolucionismo, no meu conteúdo não tem criacionismo, embora, alguns livros façam comentários sobre isto (Maria, testemunha de Jeová)

Não ensino diretamente. - Eu vou dar uma aula boje sobre o criacionismo. Não. O criacionismo surge, porque eu abro para o debate, entende? [...] O criacionismo vem. Mas eu não preparo uma aula. [...] Eu dou um espaço, em uma, duas aulas, dependendo de como for a dinâmica dos alunos, para a gente conversar sobre visões sobre a origem da vida, e o criacionismo é uma dessas visões que surgem em sala de aula. Mas tudo isto é o meu gancho para entrar em evolução da biologia, com a visão da ciência e não com a visão do criacionismo. (Nazaré, metodista)

Percebem-se, nas falas dos entrevistados, dois motivos para não ensinarem o criacionismo. O primeiro é que o criacionismo não é, no entendimento dos sujeitos da pesquisa, um conhecimento científico. Como são professores de biologia, afirmam que devem ensinar conteúdos relacionados à ciência, e não a outras formas de pensamento, como a religião. $\mathrm{O}$ segundo motivo é uma preocupação em não expor suas crenças em sala, como forma de buscar o respeito à religião dos estudantes. Assim, identifica-se uma tentativa de ser imparcial, no sentido de não impor sua crença de forma explícita, tendo em vista a diversidade religiosa de suas turmas, tal como os depoimentos a seguir.

Eu me policio muito para não deixar minha visão ficar impregnada. Talvez seja essa a razão. Mas, é porque o meu conteúdo a ser ensinado é evolução pela visão 
da ciência. [...] O meu papel como professora de ciências é contar a visão da ciência. (Nazaré, metodista)

A minha opinião sobre isto [criacionismo], eu não gosto de passar para o meu aluno. Eu não gosto de influenciar as pessoas com aquilo que eu penso, porque eu acho que você tem que formar uma opinião para pensar ou não igual a mim. Eu não posso te obrigar, entendeu? Então, eu não faço isto com o aluno. (Maria, testemunha de Jeová)

É interessante notar que Adão, Eva, Jeremias e Raquel indicam que ensinam o criacionismo e alegam que o fazem como uma forma de mostrar outras interpretações de um mesmo fato.

Numa escola pública, como é o caso da nossa, você pode colocar ou não a sua convicção, eu sempre me coloquei, eu sempre me coloquei e sempre fui muito sincero com eles: essa é a minha fé, vocês aceitem ou não, ai é vocês que têm que escolher. E a gente sempre tem os grupos agora mais fechados, mais rígidos nos seus conceitos, as igrejas pentecostais que tem aí, que são muito rígidas são muito criacionistas no sentido da Bíblia; e a gente passa a parte científica, eu não tenho porque esconder a minha fé, ai a gente passa, mas sempre deixando, respeitando muito aquilo que eles acham que deva ser o caminho deles. [...] Eu acho que é minha obrigação, passar aquilo que é científico e dentro do científico eu posso também, é um direito que eu tenho de passar aquilo que eu acredito... Aí então, isso aí sempre feito de forma muito aberta, não indo para o quadro e colocando sempre, mas sempre na base do diálogo, sempre conversando muito com eles. (Adão, católico)

No final eu explico, bom a gente tem que parar pra pensar que de repente existem criacionistas que não acreditam dessa forma, que é algo que não é estabelecido, que tem criacionismo que, en falo no que eu acredito pra eles que... Eu passo que a gente tem que dar as visões possiveis, né? Eu não acho legal também a gente só dar um tipo de visão... A gente tem que dar os lados que são relevantes... (Jeremias, presbiteriano)

Eu ensino que a origem do universo tem várias teorias. Eu falo até da questão das lendas indigenas, dos indios e aquilo... Como eu te falei eu acho que a gente não deve sonegar informações. São essas, eu cito todas. [...] A ciência vê assim e tenta explicar dessa maneira. Eu dou a aula mesmo como professor... Eu sei ser muito imparcial, entendeu? Eu não falo que é mais certo, mais errado. Que o certo boje, pode não ser daqui a alguns anos também, entendeu? As teorias são essas e vamos falar... Eu falo na criacionista... Falo lá de acordo com a Bíblia e tal... Eu dou a informação. (Raquel, católica) 
É interessante notar que Jeremias e Adão admitem apresentar o que acreditam aos estudantes, como uma forma de fazer um contraponto à visão científica. Já Raquel procura ponderar a visão científica, a sua crença religiosa e outras explicações sobre a origem da vida. As afirmações desses professores demonstram uma preocupação em apresentar a diversidade de crenças existentes e de não desvalorizá-las. No entanto, eles/as não deixam claro se apresentam as visões religiosas, mitológicas e científicas com o mesmo valor, o que poderia ser um relativismo potencialmente perigoso para a disciplina de biologia, tal como se percebe na fala de Eva.

Ensino como uma das versões sobre a origem da vida. Eu não opto por dizer que surgiu assim. Há a hipótese criacionista que se baseia nisto. Mas junto com as outras. [...] Eu acho que o aluno tem que ter todas as versões sobre a bistória. Eu acho que aluno tem que ter clareza de optar, ou por este caminho porque eu tenho consciência de que esse caminho e não o outro, entendeu? É o mais aceitável. Eu acho importante. A gente não deve omitir informação nenhuma. Se eu ensinar só o darwinismo eu não vou tá sendo coerente. (Eva, católica)

Adão, Eva, Jeremias e Raquel afirmam que mostram suas crenças aos estudantes, porém declaram que se esforçam para respeitar as suas visões. No entanto, de acordo com Cortina (1996, 2005), as religiões podem ser entendidas como "máximos de felicidade", uma vez que sua escolha é pessoal e subjetiva, ao menos atualmente e em diversos contextos. A autora afirma que o afastamento das instituições religiosas do poder público as levou para a sociedade civil, de onde podem continuar a fazer as propostas felicitantes para as quais nasceram. Além disso, Cortina (1996) alerta que é necessário que se discuta que valores os educadores podem ou não ensinar nas escolas públicas:

Os educadores também têm de saber quais são os seus "mínimos decentes" de moralidade na hora de transmitir os valores, sobretudo no que diz respeito à educação pública numa sociedade pluralista. Pois é certo que, por serem educadores, não têm legitimidade para transmitir, sem mais, apenas os valores que lhes pareçam oportunos. [...] Não seria urgente descobrir quais são os valores que podemos partilhar e que vale a pena ensinar? É ou não é urgente descobrir um "mínimo decente de valores" já partilhados? (CORTINA, 1996, p. 57-58)

Tendo em vista os argumentos de Cortina (1996), poderíamos afirmar que as práticas defendidas por estes quatro entrevistados estariam em desacordo com os "mínimos éticos" socialmente estabelecidos, pois não estariam cumprindo os seus papéis de docentes de biologia em escolas públicas, tal como defendem Nazaré e Maria. Nesse sentido, a partir da posição de Cortina (1996), é preciso que se questione a afirmação de que o professor poderia colocar suas convicções religiosas pessoais em sala de aula no mesmo patamar que o conhecimento socialmente estabelecido por uma comunidade científica e expresso nos documentos curriculares nacionais. 


\section{Conclusões}

Uma primeira conclusão possibilitada pela pesquisa foi a de que não se confirmou nossa hipótese inicial sobre uma crise de identidade entre serprofessor de biologia e professar uma fé religiosa criacionista. Para os depoentes, não há uma clara oposição entre a fé criacionista e o ensino da teoria evolutiva. Sobre suas práticas pedagógicas, eles relatam uma série de arranjos nos quais evitam ou contornam a suposta contradição entre criacionismo e evolução.

Uma segunda conclusão desta pesquisa foi a constatação de que, apesar de professarem uma fé religiosa criacionista, a maior parte dos professores afirma ensinar a evolução em suas aulas. Cabe destacar, contudo, que uma das entrevistadas (Marta) diz que não ensina esse conteúdo devido à grande resistência de alunos com visões religiosas opostas a ele. Tal dificuldade também foi relatada por outras duas professoras entrevistadas (Maria e Raquel) e constatada em outras pesquisas, como a de Cerqueira (2009). A esse respeito, Dorvillé e Selles (2009) e Dorvillé (2010) sugerem que se apresente a ciência como um campo de problematização e descobertas parciais cujo maior mérito consiste não na descoberta em si mesma, mas na possibilidade de negá-la e produzir novas explicações parciais. Acrescentam, ainda, que é importante mostrar ao/à estudante que a ausência de um "porto seguro" não é necessariamente ruim, e isso possibilitaria que, no futuro, os/as educandos/as tenham uma visão mais crítica da ciência e estejam mais preparados para acolher explicações científicas.

Uma terceira conclusão refere-se ainda ao tema da diversidade de crenças. Os depoentes declaram que buscam, ao máximo, respeitar, em sala de aula, as crenças dos estudantes. Porém, apresentam diferentes perspectivas sobre qual deve ser sua postura. Identificamos um primeiro grupo (João, Sarah, Maria e Nazaré) que prefere não expor suas crenças e declara que é fundamental ensinar o conhecimento científico. Por outro lado, quatro professores (Adão, Eva, Jeremias e Raquel) afirmam que abordam o criacionismo com a intenção de oferecer diferentes pontos de vista sobre o surgimento da vida e do universo, porém não deixam claro se dão às crenças religiosas o mesmo valor que é dado ao conhecimento científico. Como explicitamos na análise, os depoimentos desses docentes não estão de acordo com os mínimos éticos esperados para o ensino de ciências (CORTINA, 1996, 2005) e nem com o que preconizam os documentos curriculares oficiais (BRASIL, 1998, 2006). Ao se dar o mesmo valor para o criacionismo e a evolução biológica, corre-se o risco de cair em um relativismo que ignora as diferenças históricas e epistemológicas entre o conhecimento científico e o conhecimento religioso.

Uma quarta conclusão, já indicada anteriormente, é a estruturação curricular do ensino de evolução fortemente marcada pelos livros didáticos de ciências e biologia. Aqui podemos problematizar o tema da autonomia dos professores, bem como suas possibilidades de refletir e organizar os conteúdos curriculares pelos quais se sentem responsáveis pelo ensino. Essa estrutura "clássica" de organização didática dos conteúdos também foi apontada por outros estudos, como o de Almeida e Falcão (2010). Esses autores indicam que esse tipo de disposição dos conteúdos pode ocasionar distorções do ponto de vista da história e da epistemologia da disciplina acadêmica de biologia.

A quinta conclusão possível tem a ver com a formação desses professores. Percebemos que os docentes mais jovens e com formação mais recente ressaltam, com maior clareza, o caráter central e estruturante da evolução, tanto para a biologia enquanto disciplina acadêmi- 
ca quanto escolar. Aqui, levantamos a hipótese, para futuras pesquisas, de que a teoria da evolução tem ganhado mais força na formação inicial do professor de ciências e biologia.

Por fim, queremos ressaltar que as questões envolvendo ciência e religião e, mais especificamente, evolução e criacionismo estão na ordem do dia no meio acadêmico, no meio escolar e na sociedade como um todo. Devemos deixar de lado o velho ditado de que "religião não se discute" se queremos superar alguns conflitos e construir uma realidade mais plural e tolerante. E, segundo nossas conclusões, a escola não pode deixar de dar uma resposta a esse desafio.

\section{Referências}

ALMEIDA, A.; FALCÃO, J. As teorias de Lamarck e Darwin nos livros didáticos de biologia no Brasil. Ciência \& Educação, Bauru, v. 16, n. 3, p. 649-665, 2010. Disponível em: < http://dx.doi.org/ 10.1590/S1516-73132010000300010 >. Acesso em: 08 maio 2014.

ATLAS.ti 6.0. Berlin: Scientific Software Development GmbH, 2011. Disponível em: < http:// www.atlasti.com/index.html>. Acesso em: 09 maio 2014.

BERGER, P. A dessecularização do mundo: uma visão global. Religião \& Sociedade, Rio de Janeiro, v. 21, n. 1, p. 9-24, 2001. Disponível em: < http://www.iser.org.br/religiaoesociedade/public.html>. Acesso em: 08 maio 2014.

BRASIL. Ministério da Educação. Orientações curriculares para o ensino médio: ciências da natureza, matemática e suas tecnologias. Brasília: MEC, 2006.

. Ministério da Educação. Parâmetros curriculares nacionais: ensino médio, parte III ciências da natureza, matemática e suas tecnologias. Brasília: MEC, 1998

CERQUEIRA, A. V. Representações sociais de dois grupos de professores de biologia sobre o ensino de origem da vida e evolução biológica: aspirações, ambigüidades e demandas profissionais. 2009. 90 f. Dissertação (Mestrado) - Educação em Ciências e Saúde, NUTES, Universidade Federal do Rio de Janeiro, Rio de Janeiro, 2009.

CORTINA, A. Ética civil e religião. São Paulo: Paulinas, 1996.

Cidadãos do mundo. São Paulo: Loyola, 2005.

DOBZHANSKI, T. Nothing in biology makes sense except in the light of evolution. The American Biology Teacher, Reston, v. 35, n. 3, p. 125-129, mar. 1973.

DORVILLÉ, L. F. M. Religião, escola e ciência: conflitos e tensões nas visões de mundo de alunos de uma licenciatura em ciências biológicas. 2010. 357 f. Tese (Doutorado em Educação) - Faculdade de Educação, Universidade Federal Fluminense, Niterói, 2010. Disponível em: < http:/ /www.uff.br/ pos_educacao/joomla/images/stories/Teses/tese $\% 20-\% 20$ texto $\% 20 \mathrm{da} \% 20$ tese $\% 20$ final[1].pdf $>$. Acesso em: 08 maio 2014.

DORVILLÉ, L. F. M.; SELLES, S. E. Conflitos e tensões entre ciência e religião nas visões de mundo de alunos evangélicos de uma licenciatura em ciências biológicas. Enseñanza de las Ciencias, Barcelona, v. 1, p. 2757-2761, 2009. 
HENRY, J. A revolução científica e as origens da ciência moderna. Rio de Janeiro: Jorge Zahar, 1998.

MAYR, E. The growth of biological thought: diversity, evolution and inheritance. Cambridge: Harvard University Press, 1982.

. O que é a evolução. Rio de Janeiro: Rocco, 2009.

MEGLHIORATTI, F. A.; CALDEIRA, A. M. de A.; BORTOLOZZI, J. Recorrência da idéia de progresso na história do conceito de evolução biológica e nas concepções de professores de biologia: interfaces entre produção científica e contexto sócio-cultural. Filosofia e História da Biologia, São Paulo, v. 1, p. 107-123, 2006.

NERI, M. (Coord.). Novo mapa das religiões. Rio de Janeiro: FGV, 2011. Disponível em: < http:/ / www.cps.fgv.br/cps/religiao/>. Acesso em: 08 maio 2014.

RIDLEY, M. Evolução. 3. ed. Porto Alegre: Artmed, 2006.

TIDON, R.; LEWONTIN, R. C. Teaching evolutionary biology. Genetics and Molecular Biology, Ribeirão Preto, v. 27, n. 1, p. 1-8, 2004.

ZAGO, N. A entrevista e seu processo de construção: reflexões com base na experiência prática de pesquisa. In: . (Org.). Itinerários de pesquisa: perspectivas qualitativas em sociologia da educação. Rio de Janeiro: DP\&A: Lamparina, 2003. p. 285-309. 
Teixeira, P.; Andrade, M.

Apêndice A. Perfil religioso dos/as professores/as entrevistados/as

\begin{tabular}{|c|c|c|c|c|c|c|}
\hline $\begin{array}{l}\text { Professorla } \\
\text { (nome } \\
\text { fictício) }\end{array}$ & Idade & $\begin{array}{l}\text { Ano de } \\
\text { formatura }\end{array}$ & $\begin{array}{l}\text { Tempo de } \\
\text { magistério }\end{array}$ & $\begin{array}{l}\text { Sistema de } \\
\text { ensino em } \\
\text { que atua }\end{array}$ & Anos em que atua & $\begin{array}{l}\text { Especialização } \\
\text { IPós-graduação }\end{array}$ \\
\hline Adão & 59 & 1974 & 36 anos & Federal & $\begin{array}{l}\text { Licenciado para } \\
\text { cargo de direção }\end{array}$ & $\begin{array}{c}\text { Mestrado em Ensino de } \\
\text { Ciências, 2005; } \\
\text { Especialização em } \\
\text { Análise e Avaliação } \\
\text { Ambiental, } 2002\end{array}$ \\
\hline Eva & 38 & 1996 & 15 anos & $\begin{array}{l}\text { Federal e } \\
\text { Estadual }\end{array}$ & $\begin{array}{l}\text { Todo o Ensino Médio } \\
\text { regular e EJA }\end{array}$ & $\begin{array}{l}\text { Especialização (2009) e } \\
\text { Mestrado em Educação } \\
\text { Profissional e Saúde (em } \\
\text { andamento) }\end{array}$ \\
\hline Jeremias & 26 & 2009 & 5 anos & $\begin{array}{l}\text { Particular não } \\
\text { confessional }\end{array}$ & $\begin{array}{l}\text { Todo Ensino } \\
\text { Fundamental II e } \\
\text { Ensino Médio }\end{array}$ & Não \\
\hline João & 26 & 2007 & 3 anos & $\begin{array}{c}\text { Particular } \\
\text { confessional } \\
\text { católico; } \\
\text { Particular não } \\
\text { confessional }\end{array}$ & $\begin{array}{l}8^{\circ} \text { ano do Ensino } \\
\text { Fundamental, todo } \\
\text { Ensino Médio e Pré- } \\
\text { vestibular }\end{array}$ & $\begin{array}{l}\text { Mestrado em História das } \\
\text { Ciências e das Técnicas } \\
\text { e Epistemologia, } 2011\end{array}$ \\
\hline Maria & 43 & 1998 & 23 anos & Estadual & Todo Ensino Médio & $\begin{array}{c}\text { Formação para o } \\
\text { Magistério Superior, } \\
\text { 2004; Especialização em } \\
\text { Imuno-hematologia, } 2011\end{array}$ \\
\hline Marta & 43 & 1991 & 23 anos & $\begin{array}{l}\text { Municipal e } \\
\text { Estadual }\end{array}$ & $\begin{array}{l}\text { Todo Ensino } \\
\text { Fundamental II e } \\
\text { Ensino Médio }\end{array}$ & $\begin{array}{l}\text { Especialização em } \\
\text { Microbiologia (1992) }\end{array}$ \\
\hline Moisés & 28 & 2006 & 3 anos & $\begin{array}{l}\text { Particular não } \\
\text { confessional; } \\
\text { Municipal }\end{array}$ & $\begin{array}{c}\text { Todo o Ensino } \\
\text { Fundamental e } 2^{\circ} \text { e } \\
3^{\circ} \text { anos do Ensino } \\
\text { Médio }\end{array}$ & $\begin{array}{l}\text { Mestrado em Educação, } \\
2011\end{array}$ \\
\hline Nazaré & 28 & 2006 & 5 anos & $\begin{array}{l}\text { Particular } \\
\text { confessional } \\
\text { protestante; } \\
\text { Municipal }\end{array}$ & $\begin{array}{l}6^{\circ}, 7^{\circ}, 8^{\circ} \text { anos do } \\
\text { Ensino Fundamental } \\
\text { e } 1^{\circ} \text { e } 3^{\circ} \text { anos do } \\
\text { Ensino Médio }\end{array}$ & $\begin{array}{l}\text { Especialização em } \\
\text { Ensino de Biologia; } \\
\text { Mestrado em Educação } \\
\text { em andamento }\end{array}$ \\
\hline Raquel & 47 & 1986 & 26 anos & Municipal & $\begin{array}{l}7^{\circ} \text { ano Ensino } \\
\text { Fundamental }\end{array}$ & $\begin{array}{c}\text { Especialização em } \\
\text { Avaliação de Impactos } \\
\text { Ambientais e Engenharia } \\
\text { de Segurança (1989) }\end{array}$ \\
\hline Sarah & 30 & 2007 & 4 anos & Federal & $\begin{array}{l}1^{\circ} \text { Ano do Ensino } \\
\text { Médio }\end{array}$ & $\begin{array}{c}\text { Mestrado em Biologia } \\
\text { Marinha, } 2007\end{array}$ \\
\hline
\end{tabular}


Entre as crenças pessoais e a formação ...

Apêndice B. Perfil profissional dos/as professores/as entrevistados/as

\begin{tabular}{|c|c|c|c|c|}
\hline $\begin{array}{c}\text { Professorla } \\
\text { (nome fictício) }\end{array}$ & Religião & $\begin{array}{l}\text { Tempo de } \\
\text { confissão }\end{array}$ & Funções que exerce atualmente & Outras atividades \\
\hline Adão & Católico & 59 anos & Leigo & Movimento Familiar Cristão \\
\hline Eva & Católica & 38 anos & Leiga & Nenhuma \\
\hline Jeremias & Presbiteriano & 11 anos & Leigo & Nenhuma \\
\hline João & $\begin{array}{c}\text { Espírita } \\
\text { Kardecista }\end{array}$ & 23 anos & $\begin{array}{c}\text { Evangelizador de adolescentes } \\
\text { (mocidade espírita); Palestrante em } \\
\text { assuntos educacionais em reuniões } \\
\text { públicas }\end{array}$ & Nenhuma \\
\hline Maria & $\begin{array}{l}\text { Testemunha } \\
\text { de Jeová }\end{array}$ & 10 anos & Publicadora & $\begin{array}{c}\text { Pesquisadora no } \\
\text { Laboratório de Virologia } \\
\text { Molecular e Animal na } \\
\text { UFRJ/Instituto de Biologia; } \\
\text { Núcleo de Tecnologias } \\
\text { Educacionais na escola em } \\
\text { que trabalha }\end{array}$ \\
\hline Marta & Batista & 35 anos & $\begin{array}{c}\text { Participa da Escola Bíblica Dominical } \\
\text { e do Encontro de Casais }\end{array}$ & Nenhuma \\
\hline Moisés & Católico & 28 anos & Leigo & Núcleo PSOL Zona Sul \\
\hline Nazaré & Metodista & 6 anos & $\begin{array}{c}\text { Participa do Ministério do Louvor; } \\
\text { Organiza visitas a idosas do lar } \\
\text { metodista Ana Gonzaga; Participa da } \\
\text { Sociedade de Jovens }\end{array}$ & Nenhuma \\
\hline Raquel & Católica & 47 anos & Leiga & Estudante de direito \\
\hline Sarah & Católica & 20 anos & Leiga & $\begin{array}{l}\text { Grupos de estudos de } \\
\text { professores }\end{array}$ \\
\hline
\end{tabular}

